\title{
Smartphone-based application vs paper-based record: female adolescents acceptance on fluid record tool
}

\author{
Hiya Alfi Rahmah, Izka Sofiyya Wahyurin, Izzati Nur Khoiriani \& Pramesthi \\ Widya Hapsari
}

Nutrition Science Study Program, Faculty of Health Sciences, Jenderal Soedirman University, Purwokerto, Indonesia

\begin{abstract}
Introduction: Water is essential for normal functioning of the human body. Total fluid intake assessment using fluid record method is considered to be a burden for respondents, and the development of technology is expected to contribute favourably to this issue. My Fluid Diary is a smartphone-based application developed by the researcher as a fluid intake recording tool. This study aimed to evaluate the acceptance of manual, paper-based fluid intake recording compared to using My Fluid Diary as a trial among Indonesian vocational female students. Methods: A qualitative study was conducted to explore students' acceptance of fluid intake recording using the smartphone-based application. An exploratory case study approach involving 38 female students as key informants was used via focus group discussion and in-depth interview as a method of triangulation. Results: Based on the data, female adolescents admitted that the application was more acceptable for fluid intake than recording manually using a book, in consideration of three aspects - the benefits, the easiness, and the application display or features. Based on its benefits, My Fluid Diary was mentioned as easy to learn and use. However, in order to improve the application, there is still a need for research development. Conclusion: My Fluid Diary was an application with respectable acceptance for fluid record compared to the manual, paper-based method among female adolescents.
\end{abstract}

Keywords: Medical informatics application, qualitative research, adolescent

\section{INTRODUCTION}

Water is necessary for human life's survival and growth, with excessive and inadequate consumption of water having negative health effects (Zhang et al., 2018). Consuming adequate amount of water is greatly important for dehydration prevention, which occurs mostly in adolescents and affects their level of physical activity, cognitive performance, and physiological disorder in the form of subjective feelings or mood, thereby reducing productivity (Ganio et al., 2011).

Water adequacy is specifically influenced by gender and age, whereby women have higher risks to experience water deficit compared to men. Women could also be at a greater risk of dehydration since they have lower water reserves (Ritz et al., 2008). While other researchers have addressed the importance of water and hydration, water as an essential nutrient is often

\footnotetext{
*Corresponding author: Hiya Alfi Rahmah

Nutrition Science Study Program,

Faculty of Health Sciences, Jenderal Soedirman University,

Purwokerto, Indonesia

Tel/Fax: (+62) 281-6572772; e-mail:rahmah.hiyaalf@gmail.com

doi: https://doi.org/10.31246/mjn-2019-0122
} 
neglected (Rush, 2013). Furthermore, assessing fluid intake in adolescents is globally needed to know the intake patterns of different types of fluid in a day. This information is important to increase the adherence towards daily recommendation in adolescents (Guelinckx et al., 2015).

Diet records are often regarded as the gold standard, but this method needs participants to be highly motivated and have the ability to record details (Lee et al., 2017). It could be considered a burden for respondents to self-reportedly record their 7-day fluid-specific intake (Jimoh, Bunn \& Hooper, 2015). Thus, this method has limitations that could influence the results of assessment (Bardosono et al., 2015).

Technology can be seen, imagined, and described to be a potential adopter, in which the diffusion of innovation can evaluate what, why, and how ideas are adopted and communicated (Peslak, Ceccucci \& Sendall, 2012). Mobile technology can help people to record their dietary intakes and monitor them in real time (Lee et al., 2017). The results of recent studies appeared to show that there is no harm in using mobile devices to record dietary intake among participants who are familiar with mobile phone technology (Porter et al., 2016).

Recently, a new smartphone-based application named "My Fluid Diary" was developed and is available on android. This application was designed to be used as a fluid intake monitoring system, allowing users to track and input their daily fluid intakes in real time via smartphone to achieve daily fluid intake adequacy, especially from beverages. This recording tool is expected to assist respondents to selfrecord their daily fluid intakes in seven days continuously. Such an application can have considerable potential as a meaningful tool among users to input their daily fluid intakes compared to paper-based record and recall, which are known to be a burden.

As an innovation, in order to achieve development in the future, this application requires an evaluation. This study aimed to assess and evaluate My Fluid Diary's acceptance to find the differences in daily fluid intake record using two instruments - smartphonebased application and paper-based record among Indonesian female vocational students.

\section{MATERIALS AND METHODS}

This was a qualitative research designed exploration study conducted in June and July 2019. The study was carried out at SMKN 1 Banyumas, a vocational High School located in Central Java, Indonesia. Focus group discussions (FGDs) and in-depth interview as a triangulation method was used to collect data on the acceptance of female adolescents in their daily fluid record. Eligible students were capable of using, reading, and understanding the application and record book in Indonesian language.

My Fluid Diary (Figure 1) is a recent application designed to record daily intake and frequency of fluid consumption, particularly from drinks. This smartphone-based application uses android programme studio 3.2.1 with Java programme language. This androidbased application is only available in the minimum 4.0.3 version. Users need a good and stable internet connection to send data to the central server in order to use this request, so that data can be analysed by the researcher. Participants can choose their daily intake in the display of My Fluid Diary to record the portion of drinks in real time or in the same day. The recording feature also includes options of pictures, bottles, glasses, or other sizes of drink choices. The adolescents recorded their seven- 

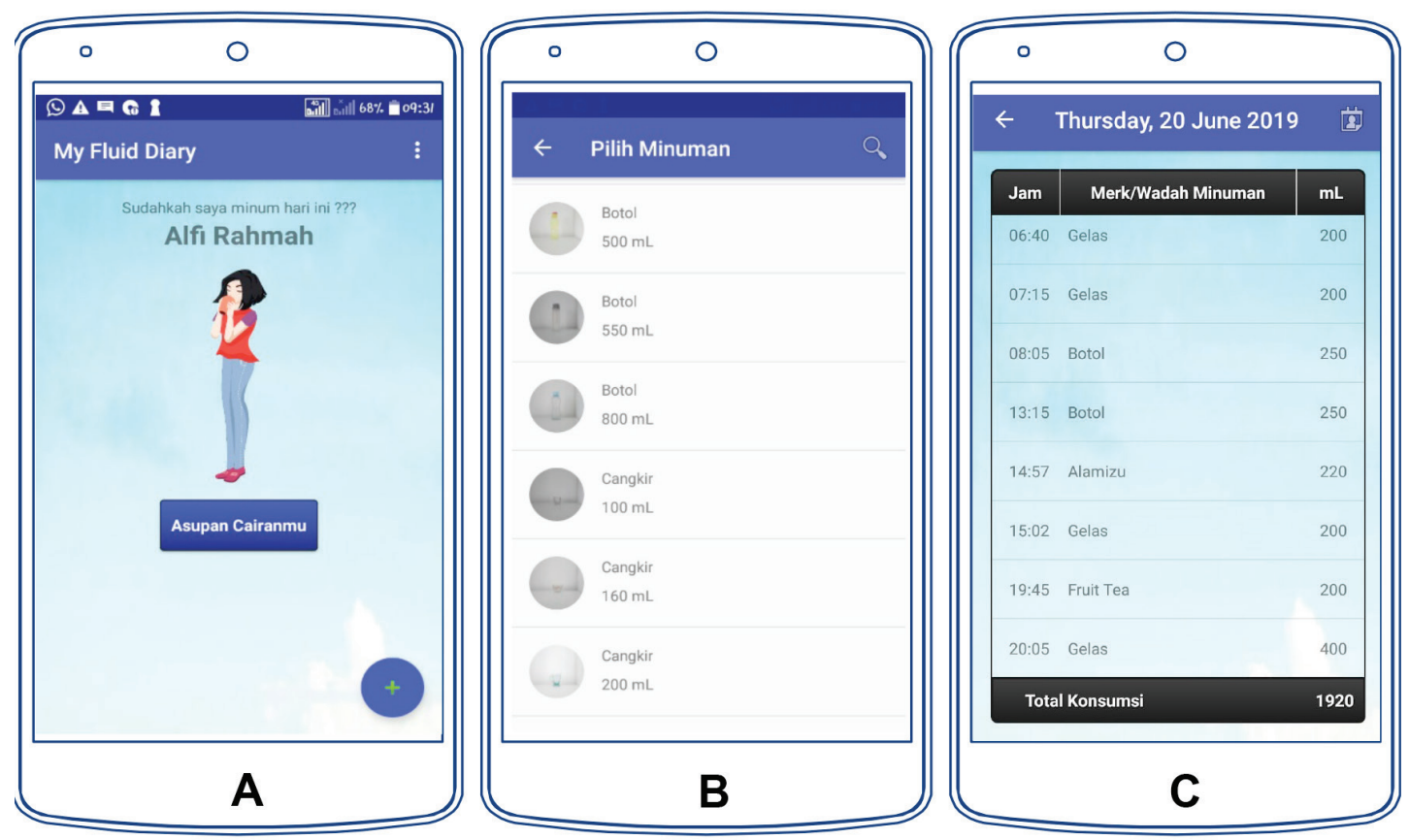

Figure 1. A. Display of "My Fluid Diary"; B. Features application for drink selection;

C. Overview of daily fluid intake

day fluid intakes using this application on their own smartphones.

Another instrument used was the paper-based fluid intake record, using a book with formatted tables in pages to manually write down their daily drink intake, size, and frequency. This record book was also complete with a module consisting of description and some photos about bottle sizes, glasses, and other drink options. Participants also recorded their seven-day fluid intakes using this instrument in order to know their perceptions and experiences.

A total of 38 students were divided into two groups of 19 students. For the first period, group A did the paperbased fluid record and group B did the smartphone-based fluid record using My Fluid Diary. After a seven-day fluid record, each group participated in the FGDs. According to FGD procedures, approximately 8-10 participants are sufficient to reach saturation recommendation (Kekalih et al., 2019).
As a result, each group was divided into small groups consisting of 9-10 students for FGDs. There were four FGDs in the first period. After a wash-out period of two weeks, during the second period, the groups switched their fluid intake record methods. After seven days of recording fluid intake, the second FGDs were used to explore their experiences. In total, eight FGDs were completed in two parts.

The eight FGDs were homogenous in composition as participants were students of the same grade and same subject of study. The students were all $8^{\text {th }}$ grade administration and office majors. Furthermore, all FGDs were done right after the students have filled out their seven-day fluid records using either paper or application. All facilitators were qualified in conducting these FGDs.

Each FGD lasted about 25 minutes, which was conducted in Indonesian language and audio recorded. All participants were told that the information collected from FGDs were 
confidential and would only be used for research purposes. Before the FGDs, all students were informed about the purpose of the study and asked to sign an informed consent.

During FGDs, three big topics were discussed. First, the students' experiences on using the fluid intake record according to the method they were using at that time. Information about first impression, opinion, benefit, and the usefulness of the methods were asked. The second topic discussed was students' opinions about the layout of the paper-based fluid diary record and "My fluid Diary". The last topic explored was their acceptance and willingness to continue recording their fluid intakes using one of these methods. In the last part of the FGDs, students' opinions on the comparison of these two recording methods were additionally asked. The topics discussed in these FGDs were perceived variables in the Innovation Diffusion Theory (IDT) that can support how technology is accepted to be adopted (Rogers 1995; Oh \& Yoon 2014).

In order to ensure the quality of the data collected, four facilitators had been recruited and trained to act as moderators, observers, note-takers, and photography or audio recording technicians. Data collection procedures and FGD guidelines were informed during training session to synchronise the facilitators' perceptions. It was an important way to optimise the role of facilitators. The role of facilitators can have a significant effect on the results and research findings. It should be considered in order to improve the trustworthiness of the research and quality of findings (Orvik et al. 2013).

As a form of triangulation, in-depth interviews were performed after every FGD. A total of 2-3 students from each FGD group were interviewed, to dig deeper on important statements. It was expected that data obtained from in- depth interviews would help and ensure that data previously obtained from FGD results were accurate.

Ethical approval for this study was obtained from the Ethical Committee of Faculty of Medicine, Universitas Jenderal Soedirman, with the number 3696/KEPK/VIII/2019. Prior to data collection, the research team had already gotten permission and also approval statement from the schools to do the research.

All data from the interviews were transcribed, then systematically analysed based on content analysis procedures by coding responses to identify the themes. Data coding is an interpretive technique to organise research data (Febrianingtyas, Februhartanty \& Hadihardjono, 2019). With this, researchers noted the themes and notable quotations.

\section{RESULTS}

The research obtained three main themes related to female adolescents' perceptions of using smartphonebased application for fluid record compared to the paper-based fluid diary record. The first theme was related to students' perceptions on the benefits of the smartphone-based application compared to the fluid diary record. The next theme was the ease of use of this application based on their acceptance, and the final theme was the students' perceptions of the application's features.

\section{Perception of the benefits}

Compared to paper-based fluid diary record, it was much more practical to use smartphone-based application. The paper-based record was not as useful as the smartphone as students were unable to carry the diary everywhere. On the contrary, nearly all students always carried their smartphones in their pockets or in anywhere, which made 
it easier to use this application. This application could also automatically save the amount of fluid intakes and different beverages that were selected in daily intake by users. Furthermore, this application could also provide them with practical ways to enter their fluid intakes.

During the time of using the paperbased method, students tended to skip or miss recording their fluid intakes. In comparison, students made real-time records after their fluid intakes using their smartphones, so this application reduced the risk of unrecorded drink intakes.

It was also less time consuming to understand and use this application. One of the students explained that compared to paper-based method, she took less than an hour to understand how to record fluid intake using the smartphone-based application:

"It took less than 10 minutes to learn this application (My Fluid Diary) until I got used to using it" (UN, 17 years old in one of the FGDs).

Another benefit offered by the smartphone-based application compared to the paper-based was the overview data on daily fluid intake (Figure 1 part C). One of the students stated that she could see her current fluid intake by using smartphone-based application and could also estimate the adequacy of her fluid intake. By inputting fluid intake into the application or book, the adolescents also knew how much their daily intake accumulation was in volume and how varied was their daily drinks.

The other benefit stated by the female adolescents was that My Fluid Diary is a modern instrument constructed based on the development of technology, so this app is suitable for them as a daily user of smartphones.

\section{Easiness of the application}

The other theme discussed in the FGDs was the easiness of the recording. Most students agreed that it was easier to use a smartphone-based application than a fluid diary record. When the smartphone-based application was first launched, most of the students already felt the easiness of the application. The students were able to easily understand the lesson about the application and to try recording their fluid intakes. By comparison, although fluid intake recording examples and guidance were given, many students still felt the difficulty with paper-based method.

"First of all, we were told to record the fluid intake using the app.., felt the ease already then after we did, it's true that using the app was easier than using the paper-based..." (S, 17 years old in one of FGDs).

The simplicity of My Fluid Diary was shown in the student's statement that this application was easy to learn and use. This application was more enjoyable due to its ease compared to the diary record book, and it did not take a long time to enter data. They also stated that image variation, description, brand, width and others were also user-friendly. By comparison, using paper-based diary fluid record was more difficult as many details had to be written manually. However, some students said it was easy to use paper-based record due to the availability of the guide and examples given.

\section{The display and features of the application}

Many students had an enjoyable view of the smartphone-based application. The simple font and suitability of the layout view made the display simpler to see. Most students also said that the blue colour used in the display was 
appropriate for the theme (fluid and water). This interesting application was also accepted for use by the students based on its friendly display and fresh features. However, some students pointed out that the use of animated pictures could make the application more interesting. They found the smaller font and columns in paper-based record made them uncomfortable to write.

One of the students suggested making the app available in offline mode so they could still record and update their fluid record without relying on internet signal. In addition, the students also highlighted the importance of updating the list of beverages and drinks, as some kinds of drinks were not included in the database. For future improvement, one of the students suggested putting fluid intake-related alarm to remind the students of using the application to do fluid intake record:

"I usually ignore the notification. It would be better if the notification came along with jingle songs, for example 'Lets drink... lets drink'. It would be much better" (AA, 17 years old on one of FGDs).

\section{DISCUSSION}

Along with technological development, health practitioners, especially dietitians, have been encouraged to create smartphone-based applications for research and practice in health promotion (Pellegrini, Pfammatter \& Conroy, 2015). User testing is necessary before an application is officially used by the community. Feedback on performance, functionality, satisfaction, incorporation into daily routine can be gathered through user testing to enhance the request. Focus group discussion is one of the common methods used to gather such information (Tonkin, Brimblecombe \& Wycherley, 2017).
The study showed that using smartphone-based application provided several advantages compared to fluid diary record in recording fluid intake. There were three advantages using the smartphone-based application practicality, the ease of recording, as well as the insightful features. These three advantages reduced the students' burden of recording their daily fluid intakes compared to paper-based record. Therefore, smartphone-based application also reduced the risk of forgetfulness and unrecorded drink intakes.

Previous studies on weight loss intervention have shown that using smartphone technologies reduced cost and burden to participants compared to traditional paper-based records (Lieffers, 2012; Martin et al., 2012; Stumbo, 2013). Other than that, along with lowered burden on recording, smartphone-based application indirectly increases participants' awareness of food intake, thereby minimising the risk of unrecorded foods (Coughlin et al., 2016).

In this research, students showed good responses on the smartphonebased application display. The display's attractiveness could be one of the contributing factors towards the students' preference for smartphonebased application compared to the diary. A scoping analysis on the features of nutrition applications on smartphones emphasised the importance of considering the use of interactive features, an attractive user interface, and non-repetitive images and colours, especially among lowsocioeconomic status and young adult groups. These functional aspects are essential to maintain engagement with the application (Tonkin et al., 2017).

Similar to other studies, students raised the importance of using the 
smartphone-based application without having to rely on internet connection. Internet connection may affect user engagement as part of the common operational problem in the application. Updated fluid database was another issue raised by the students, emphasising the importance to culturally adapt the tool according to the specific community (Tonkin et al., 2017).

This research obtained initial information about students' preferences and interest in using smartphone-based application. Information about students' experience using the application was important for its improvement. However, the results on students' preferences are enough to make smartphone-based fluid intake record as a tool to record fluid intake. Further research needs to be carried out on validating this smartphone-based application as a fluid intake record tool.

\section{CONCLUSION}

My Fluid Diary was an application with decent acceptance compared to manually paper-based recording of fluid intake among female adolescents. Students' preferences on the smartphone-based application are additional information about the benefits of nutrition-based smartphone applications. Understanding the community's experience on using the application could be useful information for researchers and developers to improve the application.

\section{Acknowledgement}

The authors thank all the respondents at SMKN 1 Banyumas, a vocational High School located in Central Java, Indonesia for their participation, as well as Nutrition Study Program, Jenderal Soedirman University, for the study conduct. The study was funded by a research grant from LPPM, Jenderal Soedirman University.

\section{Author's contributions}

HAR, principal investigator, conceptualised and designed the study, developed the application, prepared the draft of the manuscript and reviewed the manuscript; ISW, conducted the study, led the data collection and reviewed the manuscript; INK, led the qualitative data collection, data transcription, assisted in drafting of the manuscript, and reviewed the manuscript; $\mathrm{PWH}$, led the qualitative data collection, data analysis and interpretation, and reviewed the manuscript.

\section{Conflict of interest}

The authors declare that there is no conflict of interest.

\section{References}

Bardosono S, Monrozier R, Permadhi I, Manikam NRM, Pohan R \& Guelinckx I (2015). Total fluid intake assessed with a 7 -day fluid record versus a $24-\mathrm{h}$ dietary recall: a crossover study in Indonesian adolescents and adults. Eur $J$ Nutr 54(2):17-25. doi: 10.1007/s00394-0150954-6.

Coughlin SS, Whitehead M, Sheats JQ, Mastromonico J, Hardy D \& Smith SA (2016). Smartphone Applications for Promoting Healthy Diet and Nutrition: A Literature Review. Jacobs J Food Nutr 2(3):021.

Febrianingtyas Y, Februhartanty J \& Hadihardjono DN (2019). Workplace support and exclusive breastfeeding practice: a qualitative study in Jakarta, Indonesia. Mal J Nutr 25(1):129-142.

Ganio MS, Armstrong LE, Casa DJ, McDermott BP, Lee EC, Yamamoto LM, Marzano S, Lopez RM, Jimenez L, Le Bellego L, Chevillotte E \& Lieberman HR (2011). Mild dehydration impairs cognitive performance and mood of men. Br J Nutr 106(10):1535-1543. doi: 10.1017 /S0007114511002005.

Guelinckx I, Iglesia I, Bottin JH, De MiguelEtayo P, González-Gil EM, Salas-Salvadó J, Kavouras SA, Gandy J, Martinez H, Bardosono S, Abdollahi M, Nasseri E, Jarosz A, Ma G, Carmuega E, Thiébaut I \& Moreno LA (2015). Intake of water and beverages of children and adolescents in 13 countries. Eur J Nutr 54:6979. doi: 10.1007/s00394-015-0955-5.

Jimoh FO, Bunn D \& Hooper L (2015). Assessment of a self-reported drinks diary for the estimation of drinks intake by care home residents: Fluid intake study in the elderly (FISE). J Nutr Health Aging 19(5):491-496. doi: 10.1007/s12603015-0458-3.

Kekalih A, Februhartanty J, Mansyur M \& Shankar A (2019). Dietary diversity belief and practices among working mothers in Jakarta : a qualitative study. Mal J Nutr 25(Suppl):1-17. 
Lee JE, Song S, Ahn JS, Kim Y \& Lee JE (2017). Use of a mobile application for self-monitoring dietary intake: Feasibility test and an intervention study. Nutrients 9(7):E748. doi: 10.3390/nu9070748.

Lieffers JR HR (2012). Dietary assessment and self-monitoring with nutrition applications for mobile devices. Can J Diet Pract Res 73(3):253260.

Martin CK, Correa JB, Han H, Allen HR, Rood JC, Champagne CM, Gunturk BK \& Bray GA (2012). Validity of the Remote Food Photography Method (RFPM) for estimating energy and nutrient intake in near real-time. Obesity 20:891-899.

Oh J \& Yoon S J (2014). Validation of Haptic Enabling Technology Acceptance Model (HE-TAM): Integration of IDT and TAM. Telemat 31(4):585-596. doi: 10.1016/j. tele.2014.01.002.

Orvik A, Larun L, Berland A \& Ringsberg KC (2013). Situational factors in focus group studies: A systematic review, Int JQual Methods 12(1):338358. doi: 10.1177/160940691301200116.

Pellegrini CA, Pfammatter AF \& Conroy DE SB (2015). Smartphone applications to support weight loss: current perspectives. Adv Health Care Technol 1:13-22.

Peslak A, Ceccucci W \& Sendall P (2012). An empirical study of social networking behavior using theory of reasoned action. JISAR 5(3):12.

Porter J, Huggins C E, Truby H \& Collins J (2016). The effect of using mobile technology-based methods that record food or nutrient intake on diabetes control and nutrition outcomes: A systematic review. Nutrients $8(12): 1-13$. doi: $10.3390 /$ nu8120815.
Ritz P, Vol S, Berrut G, Tack I, Arnaud MJ \& Tichet $J$ (2008). Influence of gender and body composition on hydration and body water spaces. Clin Nutr 27(5):740-746. doi: 10.1016/j.clnu.2008.07.010.

Rogers E M (1995). Diffusion of Innovations (4th ed.). New York: The Free Press.

Rush EC (2013). Water: Neglected, unappreciated and under researched, Eur $J$ Clin Nutr 67(5):492-495. doi: 10.1038/ejcn.2013.11.

Stumbo PJ (2013). New technology in dietary assessment: a review of digital methods in improving food record accuracy. Proc Nutr Soc 72(1):70-76.

Tonkin E, Brimblecombe J \& Wycherley T (2017). Characteristics of smartphone applications for nutrition improvement in community settings : a scoping review characteristics of smartphone applications for nutrition improvement in community settings. Adv Nutr 8(2):308-322. doi: 10.3945/an.116.013748.

Zhang N, Morin C, Guelinckx I, Moreno LA, Kavouras SA, Gandy J, Martinez H, SalasSalvadó J \& Ma G (2018). Fluid intake in urban China: results of the $2016{\text { Liq. } \text { In }^{7} \text { national }}^{2}$ cross-sectional surveys. Eur J Nutr 57(3):7788. doi: $10.1007 / \mathrm{s} 00394-018-1755-5$. 